\title{
The Mystery of the Fifth Logical Notion (Alice in the Wonderful Land of Logical Notions)
}

\author{
Jean-Yves Beziau \\ University of Brazil \\ Largo de São Francisco de Paula 1 \\ 20051-070 Rio de Janeiro, RJ, Brazil \\ Brazilian Research Council \\ Brazilian Academy of Philosophy \\ e-mail:jyb@ufrj.br
}

\begin{abstract}
:
We discuss a theory presented in a posthumous paper by Alfred Tarski entitled "What are logical notions?". Although the theory of these logical notions is something outside of the main stream of logic, not presented in logic textbooks, it is a very interesting theory and can easily be understood by anybody, especially studying the simplest case of the four basic logical notions. This is what we are doing here, as well as introducing a challenging fifth logical notion. We first recall the context and origin of what are here called Tarski-Lindenbaum logical notions. In the second part, we present these notions in the simple case of a binary relation. In the third part, we examine in which sense these are considered as logical notions contrasting them with an example of a nonlogical relation. In the fourth part, we discuss the formulations of the four logical notions in natural language and in first-order logic without equality, emphasizing the fact that two of the four logical notions cannot be expressed in this formal language. In the fifth part, we discuss the relations between these notions using the theory of the square of opposition. In the sixth part, we introduce the notion of variety corresponding to all non-logical notions and we argue that it can be considered as a logical notion because it is invariant, always referring to the same class of structures. In the seventh part, we present an enigma: is variety formalizable in first-order logic without equality? There follow recollections concerning Jan Woleński. This paper is dedicated to his $80^{\text {th }}$ birthday. We end with the bibliography, giving some precise references for those wanting to know more about the topic.

Keywords: identity, difference, model, categoricity, invariance, square of opposition, Alfred Tarski, Adolf Lindenbaum, Jan Woleński.
\end{abstract}




\section{An Original Idea not to be Found in Logical Textbooks}

The present paper is based on a posthumous piece by Tarski entitled "What are logical notions?" [47]. Alfred Tarski $(1901-1983)$ is the most prominent logician of the $20^{\text {th }}$ century together with Kurt Gödel (1906 - 1978). Everyone interested in logic has heard of him. ${ }^{1}$

However, the theory of logical notions as presented here by Tarski is not something in the mainstream. This theory does not appear in any logical textbook! How to explain this paradox?

Tarski had a great many original ideas. Although he is very famous among philosophical logicians for his theory of truth, and among mathematical logicians for the development of model theory, many of his ideas and works are still not well-known.

The Collected Papers of Tarski (1921 - 1979), prepared by Steven Givant and Ralph McKenzie, were published in 1986 by Birkhäuser in four volumes of about 700 pages each. These volumes contain mostly photographic copies of the papers in the original language in which they were written: French, German, Polish, English, without translation and presentation. $^{2}$

At the end of the 1920s, Tarski developed the theory of the consequence operator, and for many years this theory was hardly known outside of Poland. The idea of this theory appeared for the first time in a two-page paper published in French in Poland in 1929 [43]. It was translated into English by Robert Purdy and Jan Zygmunt only in 2012, and it was published with a presentation by Jan Zygmunt in the Anthology of Universal Logic [58]. ${ }^{3}$

In addition to papers, Tarski also published some books. His famous Introduction to Logic and to the Methodology of Deductive Sciences [44], which was translated into many languages, can still be considered, after nearly one century, one of the best introductions to logic for teaching the subject. His last book was co-written with Steven Givant ${ }^{4}$ and published after his death: A formalization of set theory without variables [49]. It is also outside the main stream of the present logical theories, and it is related to the work of Ernst Schröder (1841 1902)..$^{5}$

The expression "logical notions" is not standard. A more standard way of speaking would be "logical concepts". And if we have a look at a textbook of logic and/or an encyclopedia, we will find as basic "stuffs" related to logic, things like connectives, truthtables, quantifiers, variables, constants, proof, inference, deduction, completeness, incompleteness...

If you speak about "diversity", one will imagine you are talking about politics or biology, not about a logical notion. But in this 1986 paper Tarski considers "diversity" to be a fundamental logical notion. What kind of diversity is he talking about?

In the present paper we will investigate and clarify these logical notions. Our paper is written for a large audience and can be understood by people who have little or even no knowledge of logic, showing that it is possible to go directly to the heart of logic without much sophistry.

\section{Logical Notions according to Tarski and Lindenbaum in the Perspective of a Childlike Methodology}

In "What are logical notions?" Tarski proposes to define logical notions as those invariants under any one-to-one transformation, something he presents as a generalization of an idea of Felix Klein (1849 - 1925), connected to the so-called "Erlangen program".

Tarski presented two main lectures on this topic:

- May 16, 1966, at Bedford College, the University of London, UK.

- April 20, 1973, at the State University of New York at Buffalo, USA. ${ }^{7}$ 
The paper "What are logical notions?" is related to these talks and the final version was prepared by John Corcoran who attended the second talk. Tarski approved the paper but it was published only posthumously, in 1986 in the journal History and Philosophy of Logic.

Corcoran is a famous scholar who wrote the excellent introduction to the second edition of Logic, Semantics, Metamathematics (1983) [46], a selection of papers by Tarski from 1923 to 1938, translated into English by J. H. Woodger. Since its publication this Tarski 1986 paper has been cited in hundreds of scholarly works. Currently it is first on its journal's most-cited list. It has been reprinted in The Limits of Logic, edited by S. Shapiro [41].
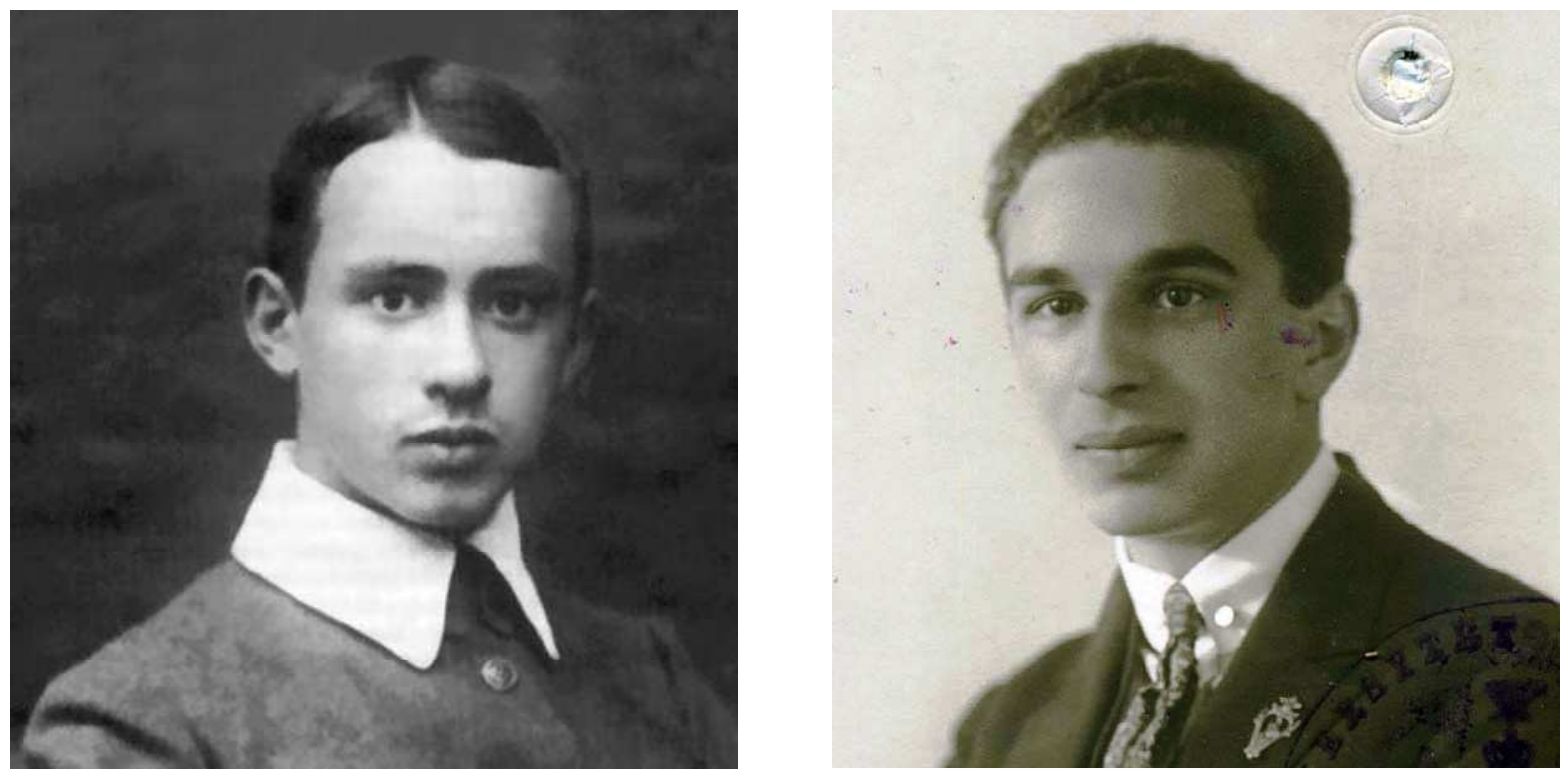

Alfred Teitelbaum and Adolf Lindenbaum

As Tarski himself says in this paper, the idea of characterizing logical notions in such a way already appears in a paper by Lindenbaum and himself in 1934 [35]. Adolf Lindenbaum (1904 - 1941) was the main collaborator and friend of Tarski when he was in Poland, so it makes sense to use the expression "Tarski-Lindenbaum logical notions" (cf. also the expression "Tarski-Lindenbaum algebra").

One may dispute the order of the name. And there is a joke in Poland saying that all the main Tarski's theorems of this period are due to Lindenbaum. Considering that Tarski's original family name was "Teitelbaum", to avoid confusion, we could create the name "A.Lindenteitelbaum" and attribute to the corresponding character the joint work, ideas and results, of these two famous logicians.

Lindenbaum-Tarski's original paper is technical but related to a particular context; on the other hand, Tarski's posthumous paper is general but rather informal. The full theory of logical notions has not yet been systematically developed, however some important advances have been made, in particular by Gila Sher [42], Vann McGee [37] and Denis Bonnay (Bonnay did a $\mathrm{PhD}$ on the topic [21], and see also his 2006 survey paper: "Logicality and Invariance" [20]). Solomon Feferman made some critical comments about Sher and McGee approaches in a paper dedicated to George Boolos entitled "Logic, Logics, and Logicism" [22]; moreover Luca Bellotti wrote an interesting study of Tarski 1986 paper simply called "Tarski on logical notions" [1].

The aim of our present paper is not to directly and explicitly develop such a theory, but to precisely analyze some aspects of it through a very simple case. Hopefully, this will contribute to the general theory. Right now there is a contrast between the fact that this 1986 Tarski paper is well- known among a small class of specialists but not among the wide class of people interested in logic, despite its profound interest. 
We will focus here on a very simple case, logical notions in the context of binary relations (presented on page 150 of Tarski 1986 paper). We believe that the careful study of simple cases is an important task. Some people may avoid doing that thinking it is not serious, that it is trivial and childish. But as Alexander Grothendieck (1928 - 2014) wrote: "Discovery is the privilege of the child: the child who has no fear of being once again wrong, of looking like an idiot, of not being serious, of not doing things like everyone else." 8 And Adolf Lindenbaum himself was interested in the question of simplicity (cf. [34]). ${ }^{9}$

Many people are afraid of being too simple, or of expressing themselves in a too simple way. If you say something simple which is wrong, then you have more chance to be detected than if you were to say something wrong in a complicated way. If you don't speak clearly and someone says that what you are saying is wrong, you can always say the person made a wrong interpretation of what you wanted to say. A common trick among sophists. Simplicity is risky. But as they like to sing in Germany: No Risk, No Fun!

There are two complementary reasons to use a childlike methodology. On the one hand by doing that one may go to the root of things, if any. On the other hand, there is a pedagogical aspect: to explain the depth and interest of a topic to people having little knowledge of it. We would be delighted and it would be wonderful if a 7-year old girl like Alice could understand this paper. And we think it is possible.

There is a tendency to underestimate the intelligence of young children. But Patrick Suppes, with whom I was working for two years at Stanford at the very beginning of this century, brilliantly showed that a 7-year old can understand many things, through his EPGY program for young children, teaching them advanced mathematics, physics, music...

This does not mean that the present paper is restricted to children; we would be even more delighted if at the same time some adults enjoy the present paper and learn something, understand something. As written by Solomon in the Proverbs (3.13): "Joyful is the person who gains understanding."

\section{The Four Tarski-Lindenbaum Logical Notions in the Case of a Binary Relation}

We consider binary relations, i.e., relations between two objects, elements, things... There are many such relations and in fact, it is possible to prove that any $n$-ary relation can be expressed/reduced to a binary relation. ${ }^{10}$ Tarski says the following about logical notions in case of binary relations:

A simple argument shows that there are only four binary relations which are logical in this sense: the universal relation which always holds between any two objects, the empty relation which never holds, the identity relation which holds only between "two" objects when they are identical, and its opposite, the diversity relation. So the universal relation, the empty relation, identity, and diversity these are the only logical binary relations between individuals. This is interesting because just these four relations were introduced and discussed in the theory of relations by Peirce, Schröder, and other logicians of the nineteenth century [47, p. $150]$.

Let us consider a binary relation on a set with two elements. The four relations can be represented by the following picture that is potato-graph-like, popular in modern mathematics, and easy to understand for Alice (cf. [38], [39]). We have put the corresponding names below each one with the obvious corresponding substantive, but we have replaced "diversity" by "difference", because this is a better name. Hopefully Tarski will forgive us. 


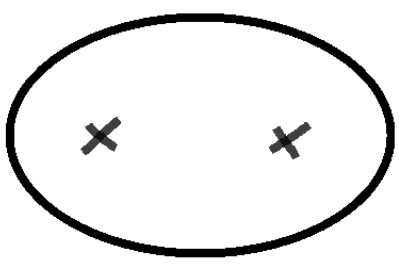

Emptiness

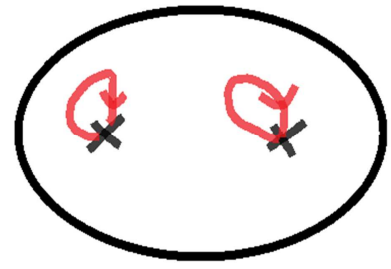

Identity

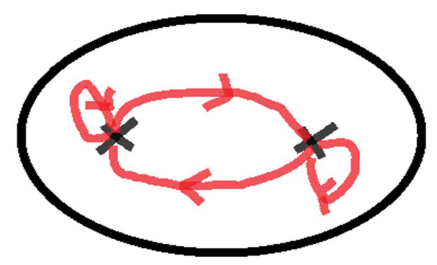

Universality

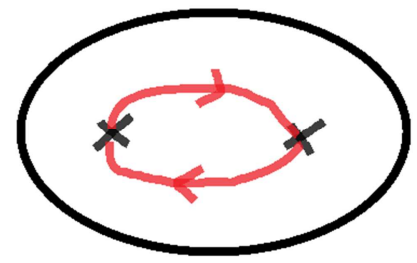

Difference

\section{An Example of a Non-Logical Relation, Formulas and Models}

Alice may ask: what does it mean that these and only these relations are logical? For example, why isn't the following one logical?

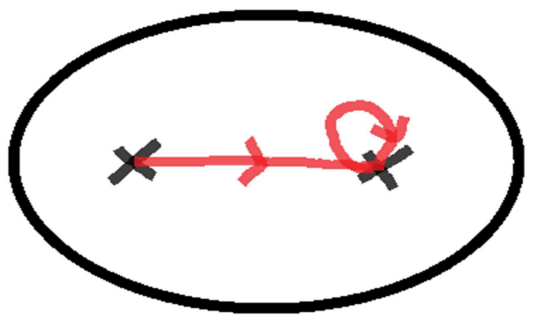

We say to Alice: try to describe this configuration (CONF1a) without giving a name to the two objects represented by the two crosses, and without referring directly to them. You cannot say, "The guy on the left is not in relation with himself" nor "There is a guy who is in relation with another guy", but you can say "There is a guy who is in relation with himself" and "There is a guy who is in relation with a guy".

Alice may propose the following description: "There is someone who is not in relation with himself but who is in relation with someone in relation with himself (so the first someone cannot be the second someone), not in relation with him". It is correct, but this is not the only possible description.

This can be transcribed into the following formula $\phi$ :

$$
\exists x(\neg(x R x) \wedge \exists \mathrm{y}((y R y) \wedge(x R y) \wedge \neg(y R x)))
$$

This is a formula of first-order logic without equality (FoLoWoE). Alice may point out that this formula also describes the following configuration (CONF1b).

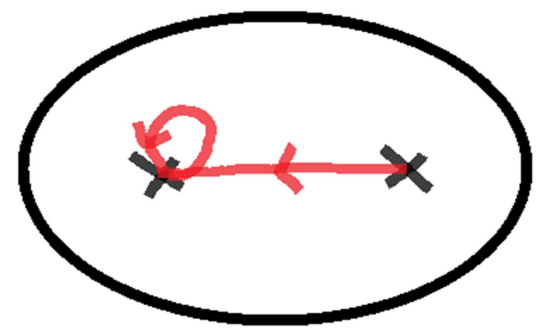

And she asks: is this not a problem? 
To reply to this question, we have to introduce model theory to Alice, a theory developed by Alfred Tarski himself. Configurations described by a formula are called models of this formula. The notion of "model" in this sense was put forward by Tarski; he developed a whole theory explaining how this works [45].

Alice's question corresponds to the following two interrelated questions:

1) Is it a problem that our formula $\phi$ describing the first configuration also has a different configuration as a model?

2) Is it possible to find a first-order formula having as a model only the first configuration?

If we allow only formulas with no specific names, no constants, only variables, the answer to question (2) is negative. And this is not necessarily a problem because these two models are considered to be isomorphic: we can establish a one-to-one correspondence between the two that preserves the given structure of this configuration, which in model theory indeed is simply called a structure. This is because what is important is the structure, not the nature of individuals, who have no existence by themselves, outside a given structure.

The two crosses have been treated by Alice as if they were human beings by using the pronoun "someone". She could have said: "There is an object" or "There is something". But her choice is good because "someone" is a single word. "Something" also is single, but its meaning is not clear in the sense that "something" can refer to anything, like a storm, with many rain drops. This is not a good means to emphasize unicity, individuality. Tarski talks about individuals: "these are the only logical binary relations between individuals" [47, p. 150].

Furthermore, "someone" gives a lively touch to our discourse, one that is more amusing than disturbing. And something fundamental is preserved in this funny way of talking: anonymity. In French at some point in modern mathematics people were using expressions such as "truc", "machin", "bidule", a sense of surrealistic poetry that unfortunately has been lost.

Now Alice asks: why is CONF1a not a logical notion? We reply to her: consider a structure with three elements. Can you see that in this case the formula $\phi$ is not categorical in the sense that it has various non-isomorphic models: for example one model in which the additional third guy has no relations with the two others and one in which he is related with one of the two:
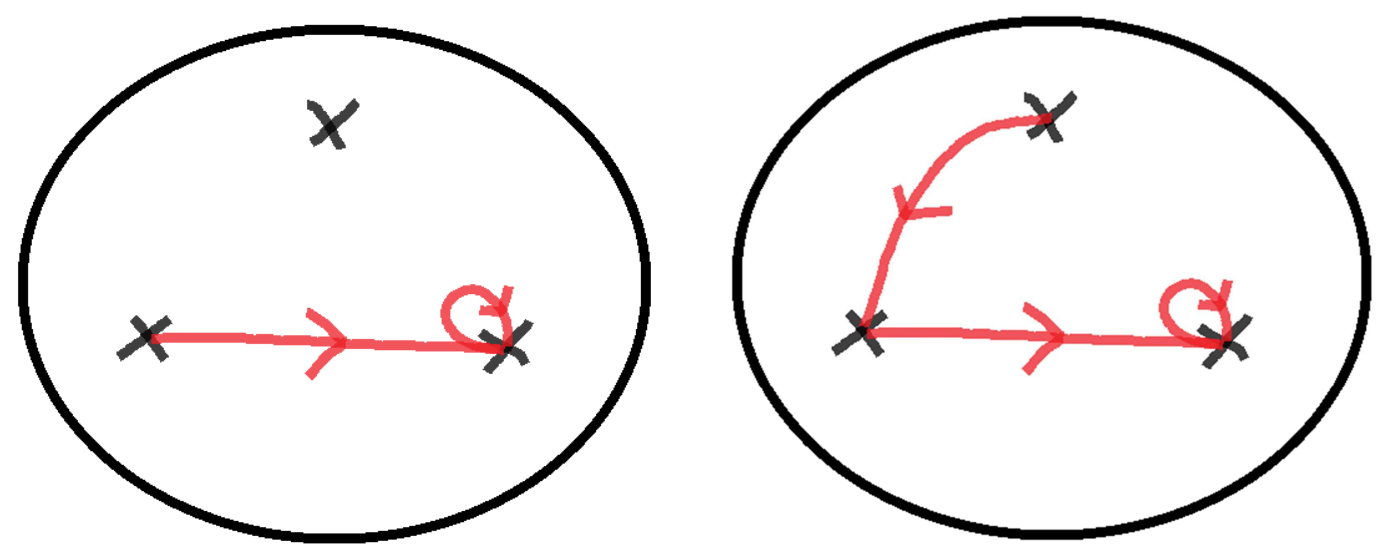

And that's the reason why:

- the formula $\phi$ does not describe a logical notion

- the relation in CONF1a is not considered as a logical notion.

Then Alice may inquire about these two reasons and their relations, asking:

(A1) As far as I understand, the formula $\phi$ does not describe a logical notion, because there is a cardinality for which it is not categorical, so categoricity is a necessary condition for logicality, but is it a sufficient reason? That is, if a formula $\psi$ is categorical for each cardinality, does $\psi$ describe a logical notion? 
(A2) If a binary relation can be described by a categorical formula, is it sufficient to consider it to be a logical notion?

(A3) Is a binary relation considered to be a logical notion only if it can be described by a categorical formula?

The reply to (A1) and (A2) is positive because Tarski-Lindenbaum's logical notions are defined by invariance, expressed here by the notions of isomorphism and categoricity. The answer to question (A3) is not so obvious.

\section{Expression and Formalization of the Four Tarski-Lindenbaum Logical Notions}

Let us investigate with Alice the formulations of the four logical notions. We first point out to Alice that, "There is someone which is not in relation with himself but who is in relation with someone in relation with himself, not in relation with him" is rather complicated. And ask her to compare with the following formulations of the four logical notions:

\begin{tabular}{|l|l|}
\hline Names & Formulations in Natural Language \\
\hline Emptiness & Nobody is in relation with anybody \\
\hline Universality & Everybody is in relation with everybody \\
\hline Identity & Everybody is in relation only with himself \\
\hline Difference & Everybody is in relation with everybody except with himself \\
\hline
\end{tabular}

The four relations have been expressed in this table using English, a natural language which spontaneously grew in the beautiful island where Alice was born. Now let us see how these four relations can be formulated in the artificial symbolic language FoLoWoE that we already presented to Alice in the previous section. Alice may draw the following table:

\begin{tabular}{|l|c|}
\hline Names & Formulas of First-Order Logic without Equality \\
\hline Emptiness & $\forall x \forall y \quad \neg(x R y)$ \\
\hline Universality & $\forall x \forall y \quad(x R y)$ \\
\hline Identity & $? ? ?$ \\
\hline Difference & $? ? ?$ \\
\hline
\end{tabular}

She put some question marks where she was not able to find a formalization using FoLoWoE. There are in fact no formulas of FoLoWoE that express the logical notions of identity and difference. It has been proven that identity cannot be expressed in first-order logic without equality (see [2], [4], [5], [7], [9], [30]). We will not present the proof here, because this can be understood only after a full year's introductory class in logic (and some people have studied logic for one thousand and one nights and still don't understand that).

But admitting this theorem, Alice can immediately understand that the difference also cannot be expressed with a FoLoWoE formula, because, if it were the case, then the negation of if would express identity. All this gives a negative answer to the third Alice's question (A3).

Alice then may ask: but how do we know that identity and difference are logical notions? We can reply to her: close your eyes and imagine a structure with 5 elements where the only arrows you have are 5 arrows rounding above each of the five crosses, a generalization of the diagram we presented previously in the case of a structure with two elements. Does not this correspond to the expression, "Everybody is in relation only with himself", in the case of a 5-element set? Can you see something else corresponding to this expression in this case? And Alice of course after opening her eyes cannot reply no. We may go further and ask her to close her eyes again and imagine a similar structure with an infinite number of crosses, and she will certainly again not reply no. 
The situation of difference is more difficult to imagine as a mental image, but we can ask Alice to draw a picture:

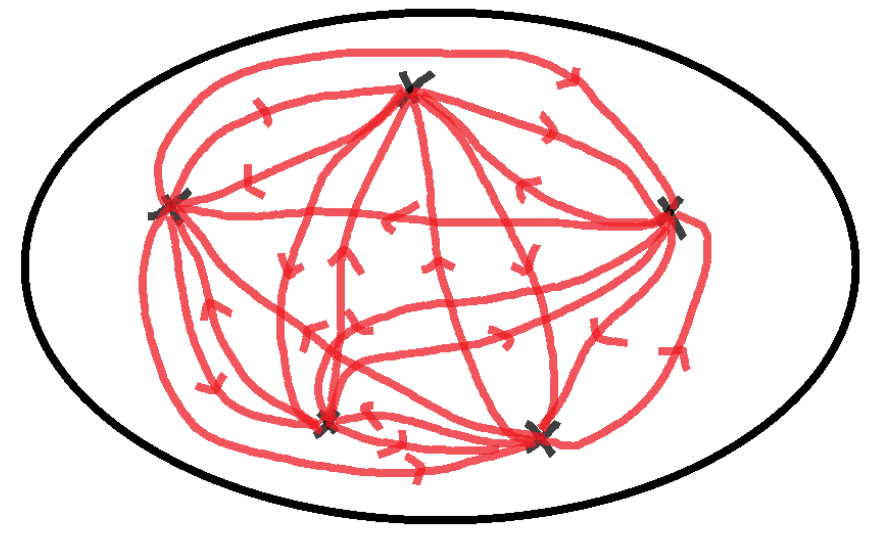

And this is the only configuration corresponding to difference in the case of a 5-element set that she can draw.

So, the situation of identity and difference is the same as the situation of universality and emptiness: they are categorical notions. But in the case of universality and emptiness this categoricity can be expressed by FoLoWoE formulas.

Alice may inquire why we forbid the use of the equality sign, "=", which is such a nice sign, invented by her cousin Robert Recorde! And she might argue that, if we lift the ban, she can express identity with the following formula:

$$
\forall x(x R x) \wedge \forall y(\neg(y=x) \rightarrow \neg(x R y) \wedge \neg(y R x))
$$

But we can say to Alice: is it not a vicious circle to define identity using equality, and is the equality sign not referring to identity? After thinking for half a second, she replies: "Sure and I don't want to be trapped in a vicious circle, long live freedom!"' (cf. [17]).

\section{Relations Between the Four Tarski-Lindenbaum Logical Notions}

Now Alice may ask: what are the relations between these four logical notions? Tarski says that the relation of difference (that he calls "diversity") is the "opposite" of the relation of identity.

According to the theory of the square of opposition, there are three different notions of opposition: contrariety, subcontrariety and contradiction. In set theory, the notions corresponding to these three oppositions are respectively, mutual exclusion (or disjointness), full intersecting union, and complementation. Only the last word is standard.

Anyway, here are some diagrams corresponding to these notions, so that Alice will perfectly understand the meaning of these words: 


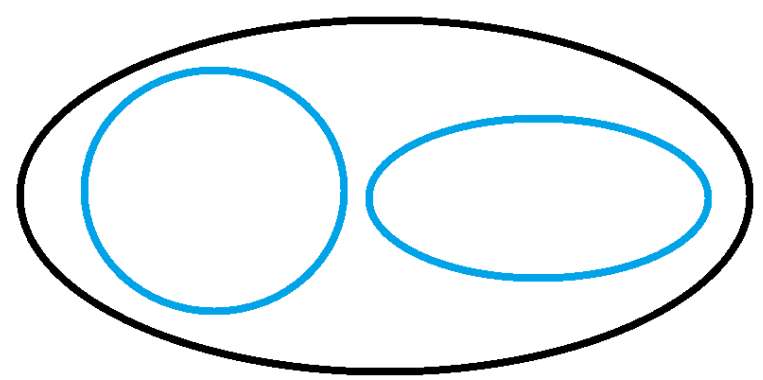

Mutual Exclusion

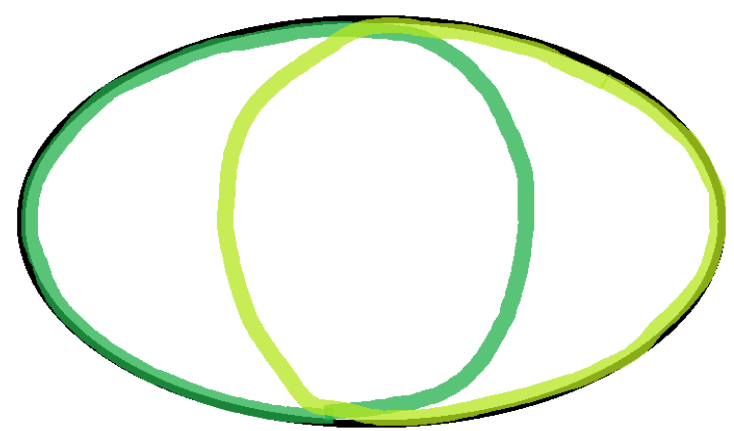

Full Intersecting Union

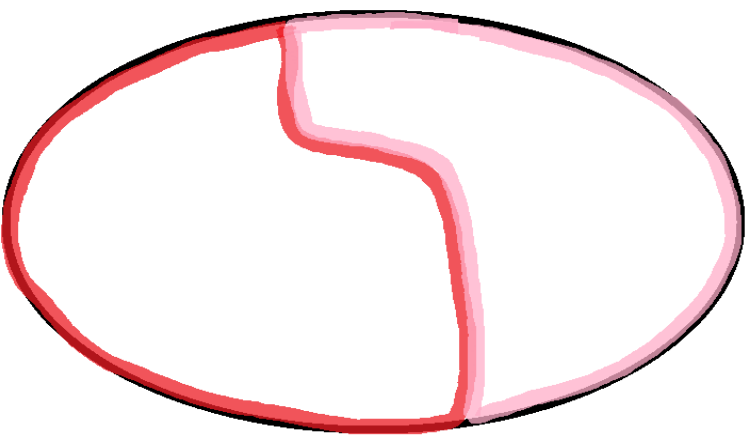

Complementation

A binary relation over a set of two distinct elements, glamorously called " $a$ " and " $b$ ", can be represented by a set of pairs. There are four possible pairs: $\langle a ; a\rangle,\langle a ; b\rangle,\langle b ; a\rangle,\langle b ; b\rangle$. The binary relation acting on them gives rise to the table below, also corresponding to what is called a Robinson's diagram - in honor of Abraham Robinson (1918 - 1974), a good friend of Tarski and also a great model-theorist.

\begin{tabular}{|c|c|c|c|}
\hline Identity & Difference & Universality & Emptiness \\
\hline$(a R a)$ & $\neg(a R a)$ & $(a R a)$ & $\neg(a R a)$ \\
\hline$\neg(a R b)$ & $(a R b)$ & $(a R b)$ & $\neg(a R b)$ \\
\hline$\neg(b R a)$ & $(b R a)$ & $(b R a)$ & $\neg(b R a)$ \\
\hline$(b R b)$ & $\neg(b R b)$ & $(b R b)$ & $\neg(b R b)$ \\
\hline
\end{tabular}

This means, in the case of the relation of identity, that this relation is the set with the only two pairs: $\langle a ; a\rangle,\langle b ; b\rangle$, and in the case of the relation of difference that it is the set with only the two pairs: $\langle a ; b\rangle,\langle b ; a\rangle$. So, from the point of view of the set of all pairs, identity is the complement of difference, and vice-versa. For this reason, we can say that these two logical 
notions are in contradictory opposition, or, simply are contradictory. And the same happens between universality and emptiness: these two logical notions are contradictory. We can therefore draw the following healthy red cross picture:

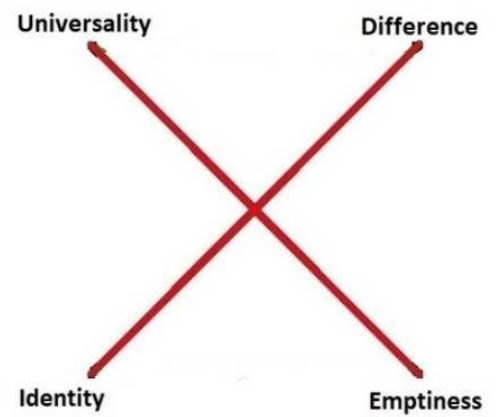

This red cross is a step towards a full square of opposition, where, besides contradiction in red, we have contrariety in blue, subcontrariety in green, ${ }^{11}$ and in black subalternation (which is not an opposition), as shown in the figure below, where at each corner we have put quantifiers, having then the most typical exemplification of the square.

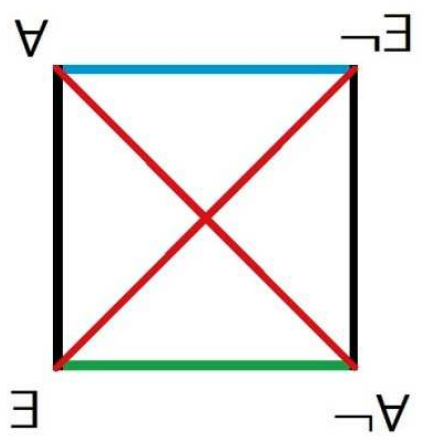

Alice may ask: can we make such a square of opposition with these four logical notions? The reply is negative. The fact that universality as a logical notion is expressed by a formula using universal quantifiers $\forall x \forall y(x R y)$ can be misleading, giving the idea that we can easily build a square of logical notions starting with the top left corner. But Alice can check that the relations between the four logical notions are properly described as follows: ${ }^{12}$

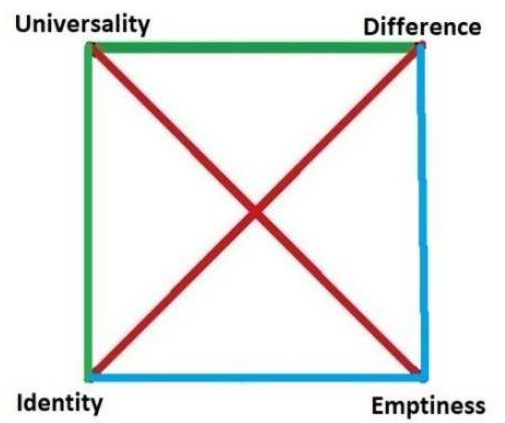

\section{The Logicality of Variety}

Besides the four structures corresponding to the four logical notions, there are in the simple case of a binary relation 12 other structures. This is just the world of combinatorics: we have a total of 16 structures for all the configurations of a binary relation over a two-element set. Among these 12 non-logical structures, half of them are reverse isomorphic images of the other ones - mirrors of them. In section 3, we have already presented two of them; here is the whole picture for Alice: 

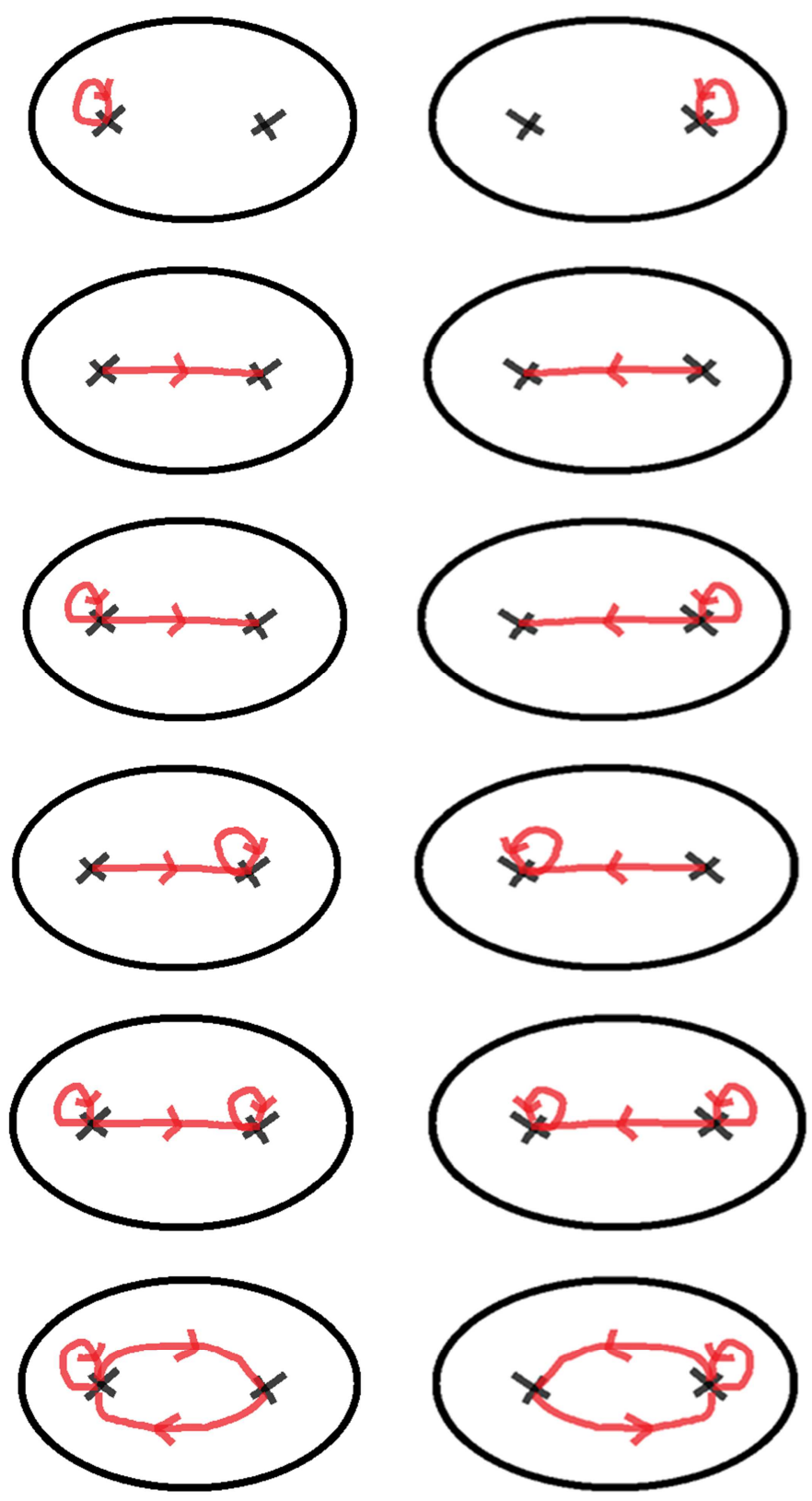

Let us consider the class of these 12 structures. It is the complement of the class of the 4 structures corresponding to logical notions. In this class of 12 structures there are nonisomorphic structures, for example:
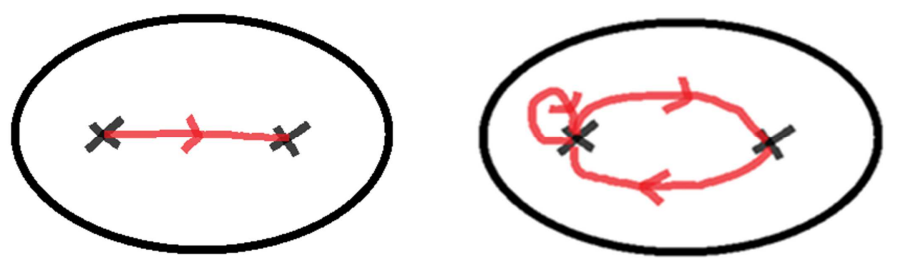

and Alice can easily be convinced that it will always be the case also for other cardinalities greater than 2. For this reason, we will say that this class corresponds to a notion, that we call variety. $^{13}$

There is invariance in this variety: for every cardinality, it always refers to the same class of models, those not corresponding to logical notions. Alice may want to qualify variety 
as a non-logical notion. And, indeed, the notion of variety collects all the non-logical relations. But since it is invariant, and since invariance is the basis of Tarski-Lindenbaum logical notions, why not also saying that variety is a logical notion, a fifth logical notion? Tarski-Lindenbaum invariance is based on isomorphism, but it can be seen from the higher perspective of notions always referring to the same classes of models.

From the point of view of classes of models, the notion of variety is the contradictory opposite of logical relations, but this is not necessarily a problem, an obstacle to calling it a logical notion; contradictory opposition is a logical concept and we can apply here the idea of the identity of opposites.

In a previous paper [14] we were not afraid to claim that anticlassical logic, i.e. the complement of the consequence relation of classical logic, can be considered as a logic, even if it is obeying none of the three Tarskian axioms for a consequence relation (reflexivity, monotonicity and transitivity). We did that with the benediction of Jan Łukasiewicz who promoted the notion of a refutation system.

Here we are claiming that variety is a logical notion with the benediction of Alice Lindenteitelbaum.

\section{An Enigma for Alice}

For a happy ending we ask Alice: is there a FoLoWoE formula $\lambda$ whose models are exactly the variety of non-logical relations (for any cardinality)?

Alice may propose the following formula $\lambda$ :

$$
\exists x \exists \mathrm{y}(x R y) \wedge \exists x \exists \mathrm{y} \neg(x R y) \wedge \exists x \neg(x R x) \wedge \exists x(x R x)
$$

having in mind the table below where each negation of a logical notion is formulated by a FoLoWoE formula:

\begin{tabular}{|l|c|}
\hline Name & Formulas of First-Order Logic without Equality \\
\hline Non- Emptiness & $\exists x \exists y(x R y)$ \\
\hline Non-Universality & $\exists x \exists y \neg(x R y)$ \\
\hline Non-Identity & $\exists x \neg(x R x)$ \\
\hline Non-Difference & $\exists x(x R x)$ \\
\hline
\end{tabular}

But this is a wrong answer! Because $\lambda$ excludes the structures on lines 2 and 5 presented in the whole picture of non-logical relations in section 6. So we will let Alice find the answer to this question before the end of the night or before the end of her life... . If she cannot find the answer by herself, we let her use as a joker MIAOU, the white cat, to whom she may ask the question (she can also have a look under the carpet): 


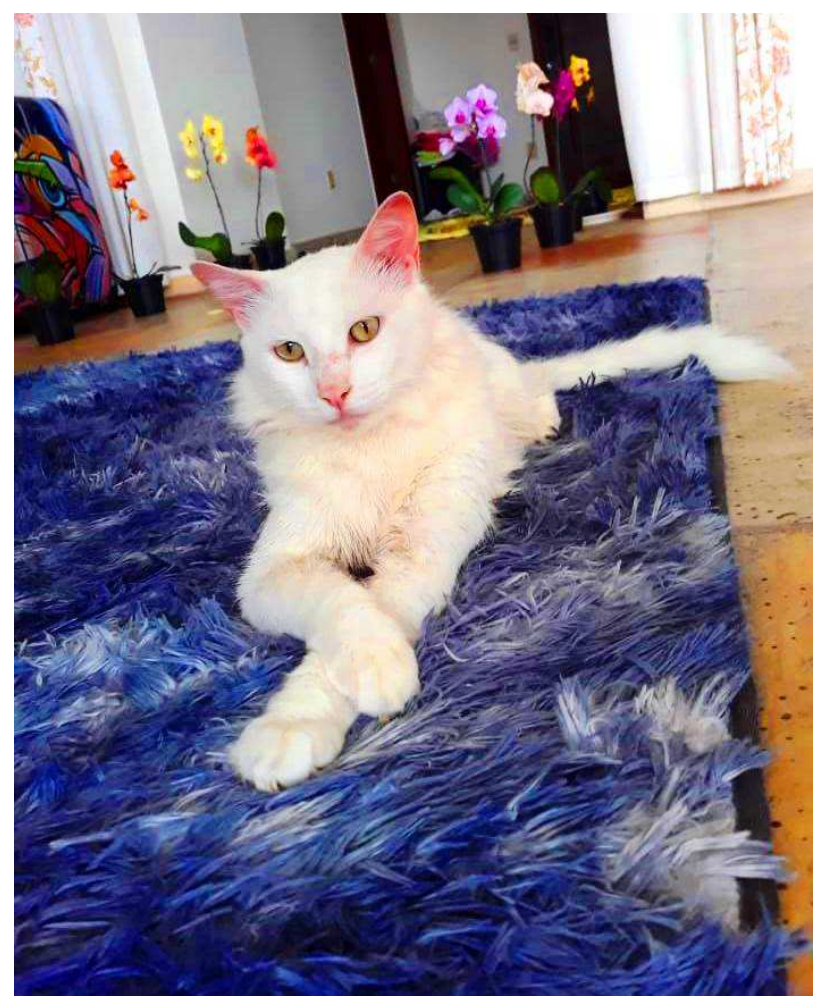

\section{Dedication and Personal Recollections}

When $\mathrm{X}$ writes a paper in honor of $\mathrm{Y}$, there are three exclusive and exhaustive categories forming a triangle of contrariety. $\mathrm{X}$ may write something which is:

(1) a critical comment of some work of $Y$

(2) related to the work of $Y$

(3) on a topic upon which $\mathrm{X}$ is working, but not in the two above categories.

The present paper clearly falls in the second category, for two reasons:

- The Polish School

- The Square of Opposition

Jan Woleński is mainly known for all the work he did to preserve and promote the history of the Lvov-Warsaw school of logic. ${ }^{14}$ But he has also developed research in many topics, including the square of opposition.

We have never worked directly together, but we have collaborated in many projects. As far as I remember, my first encounter with Woleński was at the $38^{\text {th }}$ Conference of History of Logic, November 17-18, 1992, in Kraków, Poland and the latest one at the 41st International Wittgenstein Symposium, August 5-11, 2018, in Kirchberg, Austria of which we both were invited speakers. In between we met in many other events around the world such as Logic, Ontology, Aesthetics - The Golden Age of Polish Philosophy, September 23-26, 2004, organized by Sandra Lapointe in Montreal, Canada. It would be difficult to list them all. What is important to stress is that this shows that both of us think that participation in events and interaction with colleagues are fundamental to research. Woleński also organized events. I remember in particular the 11th International Congress of Logic, Methodology and Philosophy of Science, August 20-26, 1999, Kraków, Poland, the best LMPS I took part in.

I have also organized many events, in particular, launching three series of world events:

- UNILOG: World Congress and School on Universal Logic

- SQUARE: World Congress on the Square of Opposition

- WoCoLoR: World Congress on Logic and Religion ${ }^{15}$ 
Woleński has been an invited speaker of editions of all these series. ${ }^{16}$ He was keynote at the $1^{\text {st }}$ SQUARE in Montreux, Switzerland, 2007, keynote at the $2^{\text {nd }}$ WoCoLoR in Warsaw, Poland, 2017 (logically supporting atheism), keynote at the $2^{\text {nd }}$ UNILOG in Xi' an, China, 2007.

At this event in China I also invited his former teacher Stan Surma whom he had not seen for many years (Surma emigrated during the communist period to Africa, then Australia, then New Zealand). In the photo in the next page you can see Jan Woleński circled in red, Stan Surma in green and me in blue. And you can also recognize other famous logicians such as Wilfrid Hodges, Arnon Avron, Bob Meyer, Vincent Hendricks, Arnold Koslow, Peter Schroeder-Heister, Valentin Goranko, Heinrich Wansing, etc.

Besides events, we have been collaborating in editorial projects. Jan Woleński wrote two entries for the Internet Encyclopedia of Philosophy of which I am logic area editor:

- Adolf Lindenbaum [56]

- The Semantic Theory of Truth [57]

He contributed to the volume The Lvov-Warsaw School. Past and Present edited by Á.Garrido and U.Wybraniec-Skardowska (2018) that I supervised as the managing editor of the book series Studies in Universal Logic where it was published. He wrote the following three chapters in this book:

- Alfred Tarski (1901 - 1983) [53]

- Some Philosophical Aspects of Semantic Theory of Truth [54]

- Jerzy Słupecki (1904 - 1987) [55] ${ }^{17}$

He also published a paper on the square of opposition in the journal Logica Universalis that I founded and of which I am the Editor-in-Chief:

- Applications of squares of oppositions and their generalizations in philosophical analysis (2008) [52].

For all these reasons I am very glad to contribute to this special issue and to dedicate the present paper to Jan Woleński for his $80^{\text {th }}$ birthday:

May you live actively to 120 years of age at least, Jan!

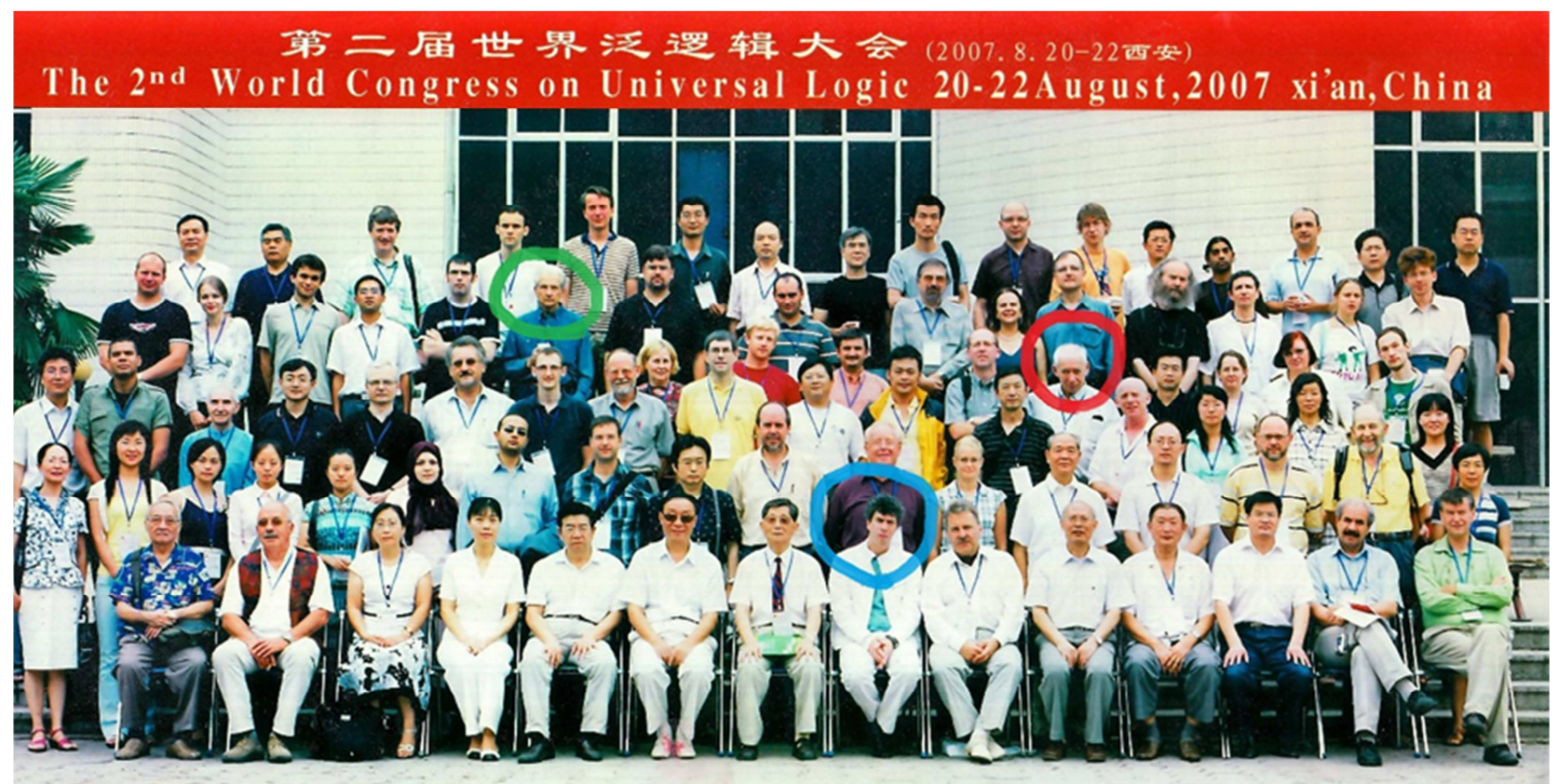




\section{Acknowledgements}

Thanks to Andrew Schumann for inviting me to contribute to this special issue. A previous version of this paper has been improved by information and comments provided by many friends : Arnon Avron, John Corcoran, Brad Dowden, Mike Dunn, Melvin Fitting, Rodrigo Freire, David Fuenmayor, Katarzyna Gan-Krzywoszynska, Val Goranko, Brice Halimi, Lloyd Humberstone, Srećko Kovač, Décio Krause, Arnold Koslow, Laurent Lafforgue, Dominique Luzeaux, David Makinson, David W.Miller, Daniele Mundici, Francesco Paoli, Daniel Parrochia, Rohit Parikh, Anca Pascu, Arnaud Plagnol, Robert Purdy, Stephen Read, Christophe Rey, Pascale Roure, Jean Sallantin, Sergey Sudoplatov, Alasdair Urquhart, Ioannis Vandoulakis, Denis Vernant, Jorge Petrucio Viana. I am grateful to all of them as well as to Alice and to my cat Miaou who both kindly took part to the project.

\section{References}

1. Bellotti, L. Tarski on logical notions, Synthese 135, 2003, pp. 401-413.

2. Beziau, J.-Y. Identity, logic and structure, Bulletin of the Section of Logic 25, 1996, pp. 8994.

3. Beziau, J.-Y. New light on the square of oppositions and its nameless corner, Logical Investigations 10, 2003, pp. 218-232.

4. Beziau, J.-Y. Quine on identity, Principia 7, 2003, pp. 1-5.

5. Beziau, J.-Y. What is the principle of identity? (identity, logic and congruence), In F. T. Sautter and H. de Araújo Feitosa (eds), Logica: teoria, aplicaçõoes e reflexões, Campinas: CLE, 2004, pp. 163-172.

6. Beziau, J.-Y. Les axiomes de Tarski, In R. Pouivet and M.Rebuschi (eds), La philosophie en Pologne 1918-1939, Paris: Vrin, 2006, pp. 135-149.

7. Beziau, J.-Y. Mystérieuse identité, In Le même et l'autre, identité et différence - Actes du XXXIe Congrès International de l'ASPLF, Budapest: Eotvos, 2009, pp. 159-162.

8. Beziau, J.-Y (ed.). Universal Logic: An Anthology, Basel: Birkhäuser, 2012.

9. Beziau, J.-Y. Identification of identity, special Dale Jacquette memorial issue of IfCoLog Journal of Logics and their Applications, J. Woods (ed.), 4, 2017, pp. 3571-3581.

10. Beziau, J.-Y. The Pyramid of Meaning, In J. Ceuppens, H. Smessaert, J. van Craenenbroeck and G. Vanden Wyngaerd (eds.), A Coat of Many Colours - D60, Brussels, 2018.

11. Beziau, J.-Y. Logic Prizes et Catera, Logica Universalis 12, 2018, pp. 271-296.

12. Beziau, J.-Y. The Lvov-Warsaw School: A True Mythology, In A. Garrido and U. Wybraniec-Skardowska (eds), The Lvov-Warsaw School. Past and Present, Basel: Birkhäuser, 2018, pp. 779-815.

13. Beziau, J.-Y. 1st World Logic Day: 14 January 2019, Logica Universalis 13, 2019, pp. 120.

14. Beziau, J.-Y. and Buchsbaum, A. Let us be Antilogical: Anti-Classical Logic as a Logic, In A. Moktefi, A. Moretti and F. Schang (eds.), Soyons logiques / Let us be Logical, London: College Publications, 2016, pp. 1-10.

15. Beziau, J.-Y., and J. Lemanski. The Cretan Square, Logica Universalis 14, 2020, pp. 1-5. 16. Beziau, J.-Y., V. Vandoulakis. The Exoteric Square of Opposition, Basel: Birkhäuser, 2020.

17. Beziau, J.-Y. Identity and equality in logic, mathematics and politics, In J.-Y. Beziau, J.P-Desclés, A. Moktefi and A. Pascu (eds), Logic in Question, Basel: Birkhäuser, 2020.

18. Beziau, J.-Y, and S. Read (eds). Special issue of History and Philosophy of Logic on the Square of Opposition 35, 2014.

19. Birkhoff, G. On the structure of abstract algebras, Proceedings of the Cambridge Philosophical Society 31, 1935, pp. 433-454. 
20. Bonnay, D. Logicality and Invariance, Bulletin of Symbolic Logic 14, 2006, pp. 29-68.

21. Bonnay, D. Qu'est-ce qu'une constante logique?, Ph.D. Dissertation, University Panthéon-Sorbone, Paris 1, 2006.

22. Feferman, S. Logic, Logics, and Logicism, Notre Dame Journal of Formal Logic 40, 1999, pp. 31-54.

23. Feferman, A. B., and S. Feferman. Alfred Tarski: Life and Logic, Cambridge: Cambridge University Press, 2004.

24. Corcoran, J. Categoricity, History and Philosophy of Logic 1, 1980, pp. 187- 207.

25. Corcoran, J. Tarski on logical notions (abstract), Journal of Symbolic Logic 53, 1988, p.1291.

26. Garrido, Á., and U. Wybraniec-Skardowska (eds). The Lvov-Warsaw School. Past and Present, Basel: Birkhäuser, 2018.

27. Givant, S. A portrait of Alfred Tarski, The Mathematical Intelligencer 13, 1991, pp. 1632.

28. Givant, S. Unifying threads in Alfred Tarski's work, The Mathematical Intelligencer 21, 1999, pp. 47-58.

29. Grothendieck, A. Récoltes et semailles - Réflexions et témoignage sur un passé de mathématicien, unpublished manuscript, 1983-1986.

30. Hodges, W. Elementary predicate logic, In D. Gabbay and F. Guenthner (eds.), Handbook of Philosophical logic, vol. I, Dordrecht: Reidel, 1983, pp. 1-131.

31. Kalmar, K. Zum Entscheidungsproblem der mathematischen Logik, Verhandlungen des internationalen Mathematiker-Kongresses Zürich 1932, vol. 2, Zurich and Leipzig: Orell Füssli, 1932, pp. 337-338.

32. Kalmar, K. Zurückführung des Endscheidungsproblems auf den Fall von Formeln mit einer einzigen, bindren, Funktionsvariablen, Compositio Mathematica 4, 1936, pp. 137-144.

33. Kalmar, K. On the Reduction of the Decision Problem. First Paper. Ackermann Prefix, A Single Binary Predicate, The Journal of Symbolic Logic 4, 1939, pp. 1-9.

34. Lindenbaum, A. Sur la simplicité formelle des notions, In Actes du congrès international de philosophie scientifique, vol. VII, Logique, Paris: Hermann, 1936, pp. 28-38.

35. Lindenbaum, A., and A. Tarski. Über die Beschränktheit der Ausdrucksmittel deduktiver Theorien, In Ergebnisse eines mathematischen Kolloquiums, fasc. 7, 1934-1935, pp. 15-22. Reproduced in A. Tarski, Collected Papers, Vol.1 1921-1934, Vol.2 1935-1944, Vol.3. 19451957, Vol.4 1958-1979, Edited by S. Givant and R. McKenzie, Birkhäuser, Basel, 1986.

and translated into English in A. Tarski, Logic, semantics, metamathematics, 2nd ed. (J. Corcoran), Indianapolis: Hackett, 1983. [1st ed. and transl. by J. H. Woodger, Oxford, 1956, pp. 384-39.

36. Łukasiewicz, J. O zasadzie sprzeczności u Arystotelesa, Kraków: Akademia Umiejętności, 1910

37. McGee, V. Logical operations, Journal of Philosophical Logic 25, 1996, pp. 567-580.

38. Papy, G. Mathématique moderne, 1-6, Paris: Didier, 1963-1967.

39. Papy-Lenger, F. and G. Papy. L'enfant et les graphes, Paris: Didier, 1969.

40. Purdy, R., and J. Zygmunt. Adolf Lindenbaum, Metric Spaces and Decompositions, In A. Garrido and U. Wybraniec-Skardowska (eds), The Lvov-Warsaw School. Past and Present, Basel: Birkhäuser, 2018, pp. 505-550.

41. Shapiro, S. (ed.). The Limits of Logic, Dartmouth Publishing Company, Aldershot, 1996.

42. Sher, G. The bounds of logic, Cambridge: MIT Press, 1991.

43. Tarski, A. Remarques sur les notions fondamentales de la méthodologie des mathématiques, Annales de la Société Polonaise de Mathématiques 7, 1929, pp. 270-272. English translation by R .Purdy and J. Zygmunt in J.-Y. Beziau (ed.), Universal Logic: An Anthology, Basel: Birkhäuser, 2012, pp. 67-68].

44. Tarski, A. O Logice Matematycznej i Metodzie Dedukcyjnej, Atlas, Lvov-Warsaw, 1936. 
45. Tarski, A. Contributions to the theory of models. I, II, III, Indigationes Mathematicae 16, 1954, pp. 572-581, pp. 582-588, 17, 1955, pp. 56-64.

46. Tarski, A. Logic, semantics, metamathematics, 2nd ed. (J. Corcoran), Indianapolis: Hackett, 1983. [1st ed. and transl. by J. H. Woodger, Oxford, 1956].

47. Tarski, A. What are logical notions? (ed. by J. Corcoran), History and Philosophy of Logic 7, 1986, pp. 143-154.

48. Tarski, A. Collected Papers, Vol.1 1921-1934, Vol.2 1935-1944, Vol.3. 1945-1957, Vol.4 1958-1979, Edited by S. Givant and R. McKenzie, Birkhäuser, Basel, 1986. Reviewed by J. Corcoran in Mathematical Reviews (91h:01101, 91h:01101, 91h:01103, 91h:01104). Reprinted by Birkhäuser, Basel, 2019.

49. Tarski, A., and S. Givant. A formalization of set theory without variable, Providence: American Mathematical Society, 1987

50. Tarski, A., J. Tarski, and J. Woleński. Some Current Problems in Metamathematics, History and Philosophy of Logic 16, 1995, pp. 159-168.

51. Woleński, J. Logic and Philosophy in the Lvov-Warsaw School, Dordrecht: Kluwer, 1989.

52. Woleński, J. Applications of squares of oppositions and their generalizations in philosophical analysis, Logica Universalis 1, 2008, pp. 13-29.

53. Woleński, J. Alfred Tarski (1901-1983), In A. Garrido and U. Wybraniec-Skardowska (eds.), The Lvov-Warsaw School. Past and Present, Basel: Birkhäuser, 2018, pp. 361-371.

54. Woleński, J. Some Philosophical Aspects of Semantic Theory of Truth, In A. Garrido and U. Wybraniec-Skardowska (eds.), The Lvov-Warsaw School. Past and Present, Basel: Birkhäuser, 2018, pp. 373-389.

55. Woleński, J. Jerzy Słupecki (1904-1987), In A. Garrido and U. Wybraniec-Skardowska (eds.), The Lvov-Warsaw School. Past and Present, Basel: Birkhäuser, 2018, pp. 567-573.

56. Woleński, J. Adolf Lindenbaum, The Internet Encyclopedia of Philosophy, https://www.iep.utm.edu/lindenba/, 2020.

57. Woleński, J. The Semantic Theory of Truth, The Internet Encyclopedia of Philosophy, https://www.iep.utm.edu/s-truth/, 2020.

58. Zygmunt, J. Tarski's first published contribution to general mathematics, In J.-Y. Beziau, (ed.), Universal Logic: An Anthology, Basel: Birkhäuser, 2012, pp. 59-66.

59. Zygmunt, J., and R. Purdy. Adolf Lindenbaum: Notes on His Life with Bibliography and Selected References, Logica Universalis 8, 2014, pp. 285-320.

\section{Notes}

1. I have launched in 2019 the World Logic Day, celebrated in 60 locations all over the world on January 14, the day of birth of Tarski and of the death of Gödel (cf. [13]), and subsequently made the proposal to UNESCO to recognize this day. It officially entered into the UNESCO calendar of international days in 2020. Before that I managed to launch in Poland the Alfred Tarski Prize of Logic, part of the project A Prize of Logic in Every Country! (cf. [11]).

2. Each of these four volumes has been reviewed by Corcoran in Mathematical Reviews in 1991 (see [48]). During many years they were out of stock. They have been re-issued by Birkhäuser in 2019 [48].

3. We are preparing a volume with posthumous papers (such as the one here discussed) and correspondence (to be published also by Birkhäuser).

4. Givant wrote two interesting papers in The Mathematical intelligencer about Tarski for a general audience (see [27] and [28]) and there is also the book by Solomon and Anita Feferman about Tarski's life and work [23].

5. As Jan Woleński pointed out [51], the first introduction to modern logic in Poland is a presentation of Schröder's logical ideas as an appendix to Łukasiewicz's book about the 
principle of contradiction in Aristotle [36]. Jan Łukasiewiecz (1878-1956) was, together with Stanisław Leśniewski (1886-1939), the main teacher of Tarski.

6. Tarski also used the word "notion" in the title of his 1929 paper [43] about consequence operator (in French, but this is exactly the same word, syntactically and semantically, as in English). In this paper he presents the consequence operator as a fundamental notion of the "methodology of mathematics" which for him is here synonymous with "logic". I have recently developed a theory about notion (cf. [10] ) in harmony with Tarski's use of this word in his 1929 paper and his 1986 paper.

7. Rohit Parikh reported that he attended a similar talk by Tarski at Bristol University (UK) at about the same period as the talk in London and Michael Dunn attended also a similar one at Rice University (Houston, USA), in January 1967. I am grateful to both of them to have informed me about that.

8. First paragraph of "L'enfant et le bon Dieu", first chapter "Rravail et découverte" of the first part of "Fatuité et renouvellement of Grothendieck's autobiography Récoltes et Semailles [29] (thanks to Laurent Lafforgue for the precise reference).

9. I have been quite influenced by some ideas of Lindenbaum and for this reason, I have been working at making his work better known. This has resulted in the publication of three papers about his life and work: [59], [40] and [56].

10. See [31], [32], [33]. I am grateful to Lloyd Humberstone for these references.

11. We have introduced this coloring of the square in [3]. For recent developments on the square of opposition see [15] and [16]. There is also a special issue of the journal History and Philosophy of Logic on the square [18].

12. Thanks to Arnon Avron who pointed out the incompleteness of a previous version of this diagram.

13. The word "variety" is used with a different meaning in Universal Algebra, cf. the famous HSP theorem [19]. But this use is rather artificial, not directly connected to the meaning of the word in natural language.

14. His main book on the subject is [51] but he published/edited lots of other books on the topic. He also edited together with the son of Tarski an interesting posthumous paper by Tarski [50].

15. This series of events was launched together with my colleague Ricardo Silvestre.

16. He was also keynote speaker at the $1^{\text {st }}$ World Congress on Analogy in Puebla, Mexico, November 4-6, 2015; an event I co-organized with Juan Manuel Campos Benítez and Katarzyna Gan-Krzywoszyńska. I remember a long discussion I had with him on the bus going back from Puebla to Mexico International Airport.

17. This book was launched at the $6^{\text {th }}$ UNILOG in Vichy, France in June 2018, with the participation of Woleński. 